\title{
Indicator Mineral Analysis of Stream Sediments Bordering the North American Emerald Mine in Alexander County, North Carolina
}

Anabel G. Winitsky and Dr. Brittani D. McNamee

Department of Environmental Studies, University of North Carolina at Asheville, Asheville NC ANASHEVILLE

\section{INTRODUCTION}

The North American Emerald Mine (NAEM), located in Alexander County North Carolina, contains V-Crbearing beryl deposits that have produced the most valuable emeralds ever found in North America', and is the first confirmed location of Cr-bearing spodumene, known locally as hiddenite ${ }^{2}$. These emeralds occur within hydrothermal quartz veins in open cavities, in one of four distinct cavity types identified by Wise and Anderson that run throughout the Inner Piedmont Belts of Western North Carolina ${ }^{3}$. This project further analyzes the NAEM through an analysis of the dense stream sediments sampled from the Wallace Creek and the South Yadkin River, which converge in the southeast and border the mine site. Stream sediments are an excellent source of indicator minerals, which serve to provide geologic context, as they consolidate high density minerals and allow for their convenient recovery ${ }^{4}$. In this application, indicator minerals are used to identify potential emerald cavity locations along the fluvial systems.

METHODS
- Samples were collected using sluicing methods to
obtain dense sediments from Wallace Creek and
Yadkin River $11 / 2 / 2018$.
- Glass slides of each sample were prepared with
$1.560,1.600$, and 1.650 indicator liquids for visual
and optical analysis by SLM and PLM.
- C-coated sprinkle mounts and polished epoxy
grain mounts were prepared for visual analysis by
SEM and compositional analysis by EDS.
- Polished epoxy grain mounts were further
analyzed for compositional data by EMPA.
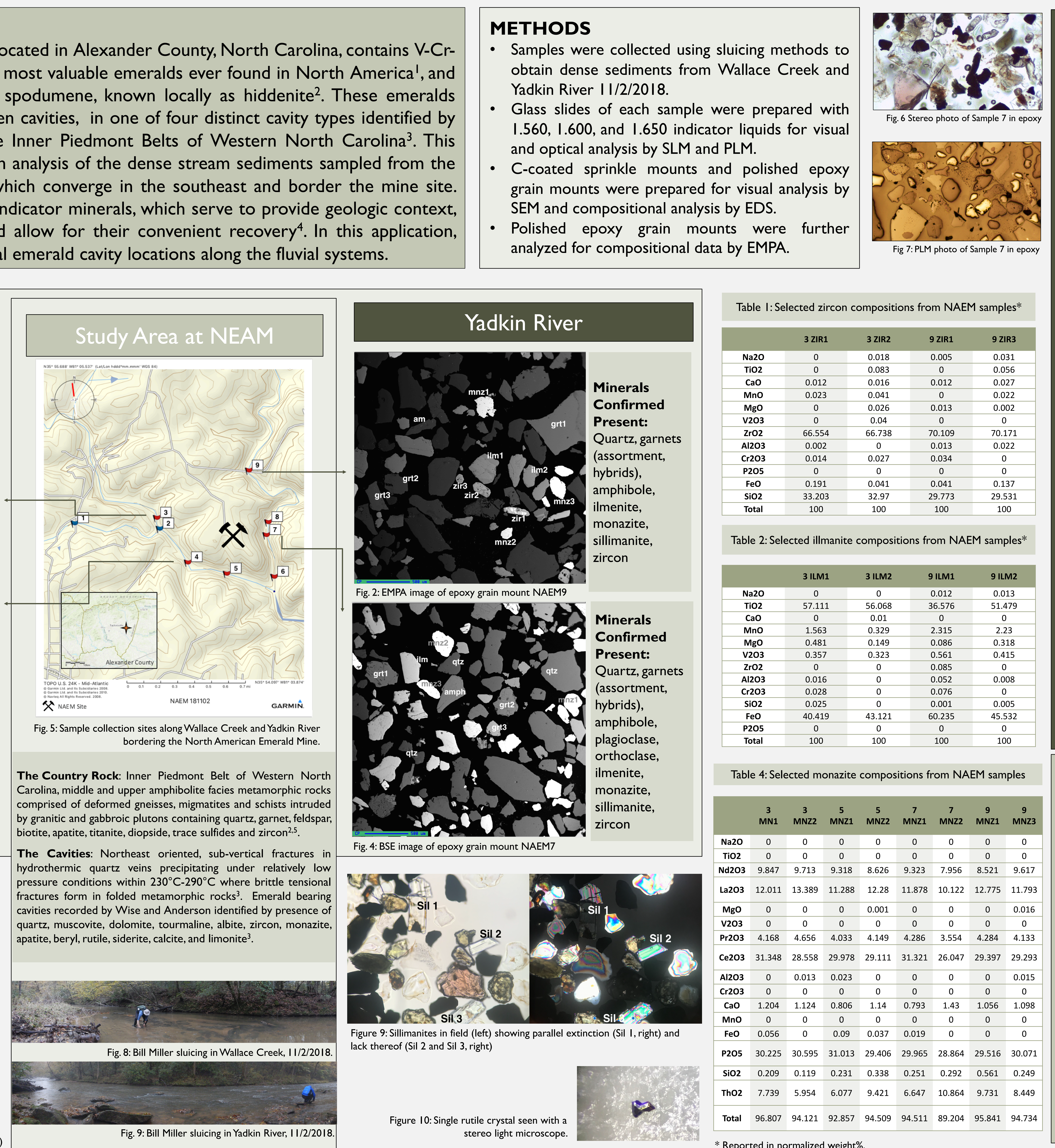

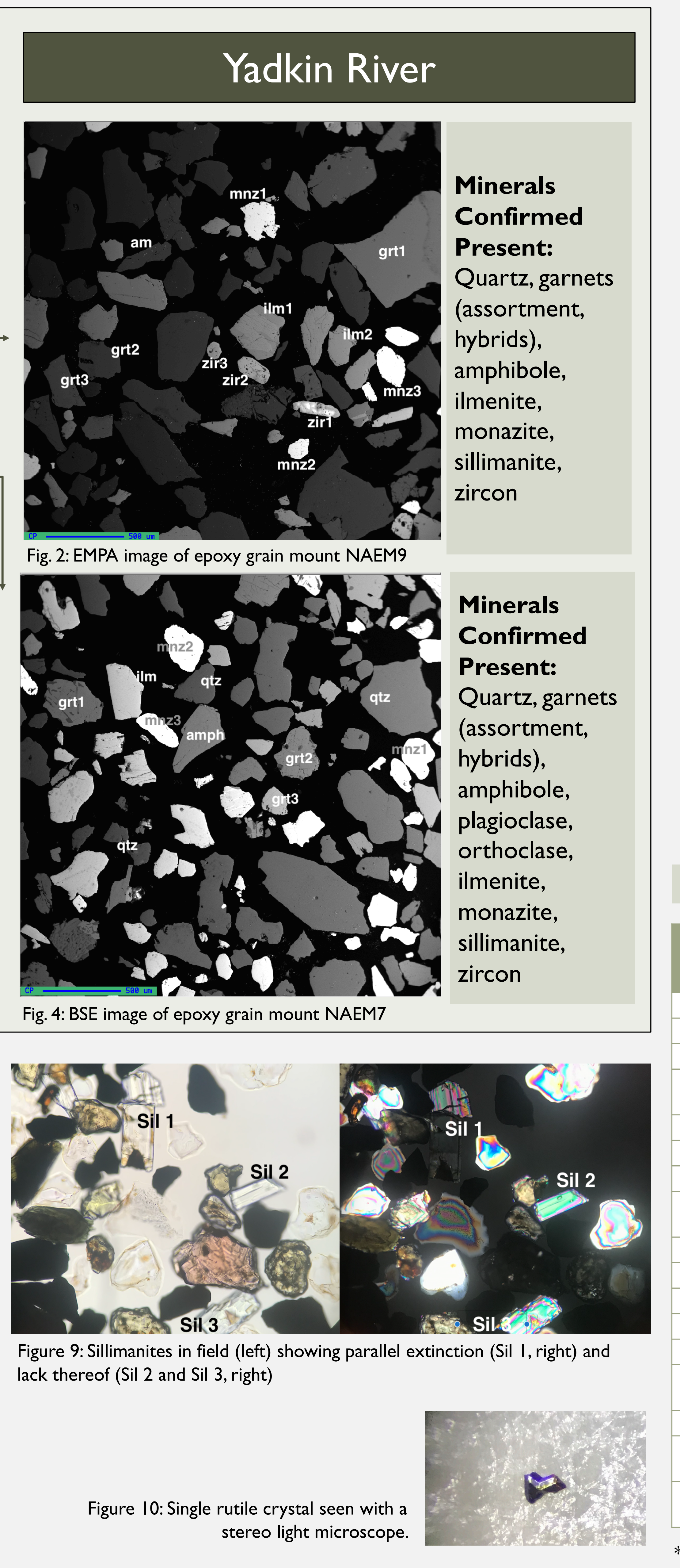

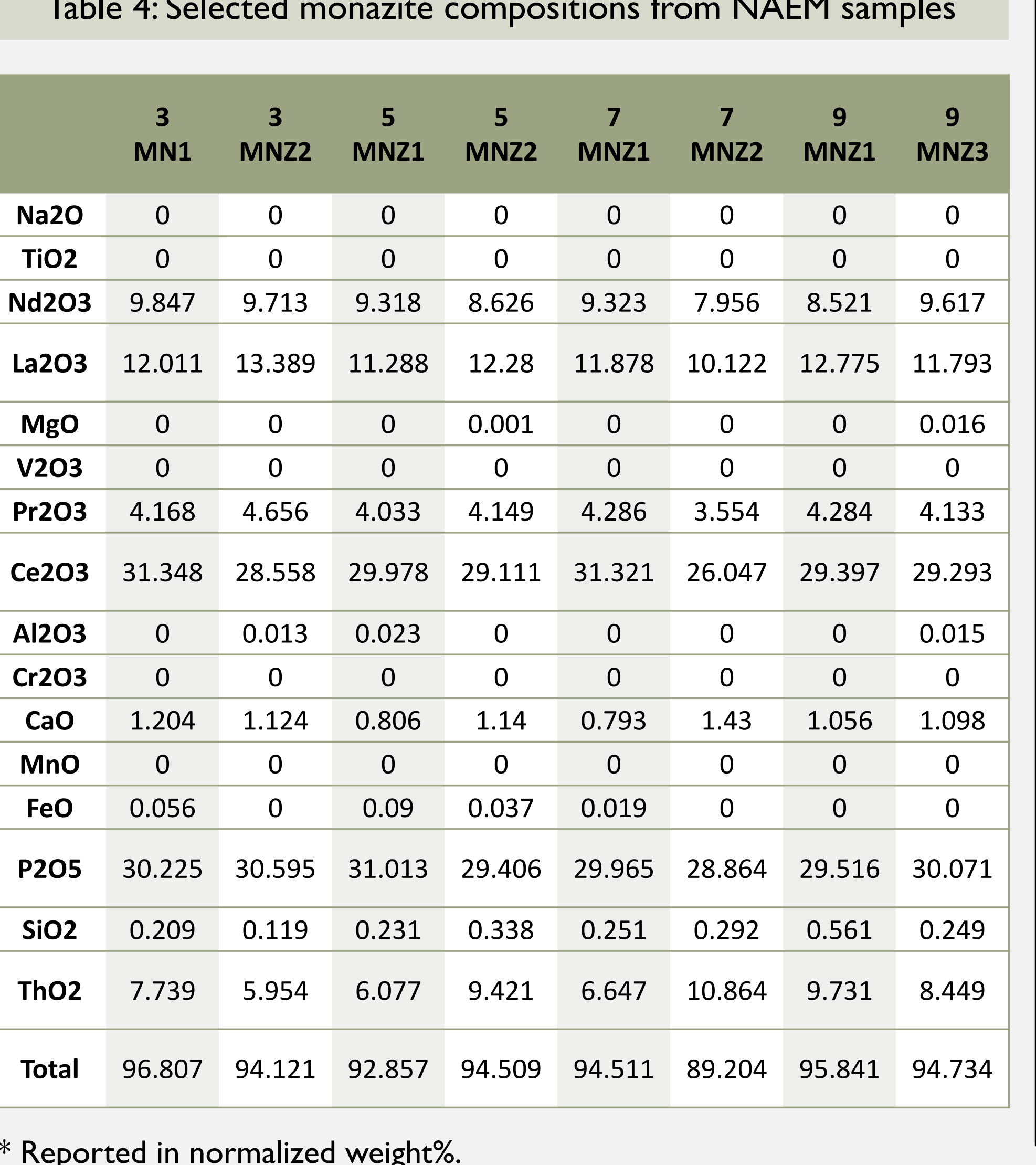

\section{CONCLUSION}

This work further characterizes the indicator minerals of the host rock and within the four cavity types present at NAEM site. Specimen location is correlated to previous research to etermine presence of cavities in river path/deposition area.

Quartz, assorted garnets, amphiboles, ilmenite, sillimanite, monazite and zircon were found in all samples

Garnets vary with almandine, spessartine, grossular hybrids common throughout samples.

Zircons vary in trace element presence throughout samples. - Monazites (Ce, La, Nd, Th) had consistently higher La and lower $\mathrm{Nd}$ (averaging I I.7:8.9 w/w\%), inverse to ratios previously found in emerald cavities by Wise and Anderson throughout samples.

- Ilmenites with higher $\mathrm{Cr}$, and V present in Yadkin River. Tourmaline presence in sample 5 may indicate cavity presence which may have come from previously explored mine site.

Rutile and tourmaline presence in 3 may indicate cavity presence along Wallace Creek north of mine site.

\section{FUTURE RESEARCH}

Research is ongoing. Future research may include:

Continuing SEM and EDS analysis with a focus on detection of $\mathrm{Cr} / \mathrm{V}$-beryl and Cr-spodumene.

Spindle stage analysis of individual crystals to further confirm and determine indicator minerals present.

Bulk phase analysis to determine relative mineral

concentrations in the fluvial systems.

Further EMPA analysis for more complete compositional data and comparative analysis.

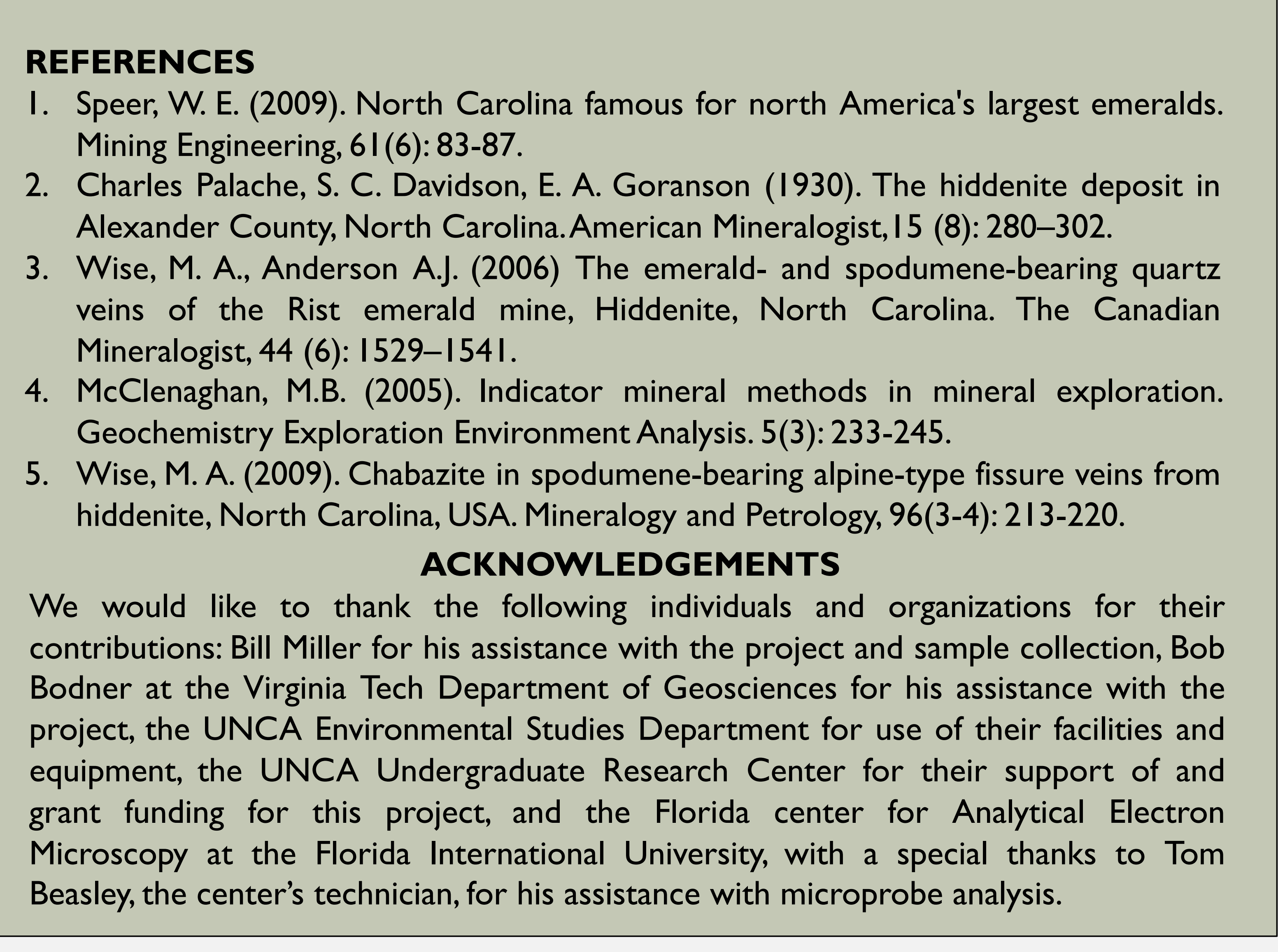

